Article

\title{
Sustainability as a Key Factor in Tourism Competitiveness: A Global Analysis
}

\author{
Beatriz Rodríguez-Díaz ${ }^{1, *(1)}$ and Juan Ignacio Pulido-Fernández ${ }^{2}$ (i) \\ 1 University Institute of Tourist Investigation, Intelligence and Innovation, Department of Applied \\ Economics (Mathematics), University of Malaga (Universidad de Málaga), Campus Ejido, s/n, \\ 29071 Malaga, Spain \\ 2 Laboratory of Analysis and Innovation in Tourism (Laboratorio de Análisis e Innovación \\ Turística-LAInnTUR), Department of Economics, University of Jaen (Universidad de Jaén), Campus Las \\ Lagunillas, s/n Edificio D3-273, 23071 Jaen, Spain; jipulido@ujaen.es \\ * Correspondence: brodriguez@uma.es
}

Received: 16 October 2019; Accepted: 13 December 2019; Published: 19 December 2019

check for updates

\begin{abstract}
The aim of this study is to analyze the relationship between sustainability and tourism competitiveness and potential differences in these parameters between geographical regions. The Travel and Tourism Competitiveness Index (TTCI) of the World Economic Forum is most commonly used to measure tourism competitiveness, however, this index has been criticized by some academics. We propose a synthetic indicator $\left(\mathrm{I}^{\mathrm{m} \alpha}\right)$ using the multicriteria double reference point method, which can measure tourism competitiveness more accurately by applying different degrees of substitutability among pillars. The Sustainable Development Index (SDG Index) frames the implementation of Sustainable Development Goals and was used to analyze sustainability data. The new tourism competitiveness index $\left(\mathrm{I}^{\mathrm{m} \alpha}\right)$ was obtained at both the global and regional level. It is important to note that some countries have a different ranking in the regional and global tourism competitiveness indexes, which shows a different behaviors among regions. The relationship between sustainability and tourism competitiveness is positive in all the analyses performed, though it is stronger when calculated without allowing substitutability, especially when considering the regional index. These trends show the value of this regional study of tourism competitiveness, because in addition to helping managers develop strategies to improve tourism competitiveness, it allows them to know the effect that these strategies will have on sustainability.
\end{abstract}

Keywords: competitiveness; tourism; sustainability; synthetic index; World Economic Forum

\section{Introduction}

Tourism destination competitiveness (TDC) is highly relevant in the academic field and has been studied for more than 30 years. All tourism activities have an environmental footprint, and activities such as travel, accommodation, and food production and consumption can have negative impacts if not adequately managed. However, tourism has several benefits, including the higher involvement of administrative agencies in conserving natural resources, creation of economic value, regional development, and environmental and cultural heritage protection. Tourism integrated into local communities, distanced from mass tourism, is necessary to provide a more realistic experience, which raises awareness of the need to preserve the traditions of local communities and their surroundings and practice sustainable tourism.

In September 2015, during the Special Summit on Sustainable Development, the United Nations member states approved the 2030 Agenda for Sustainable Development, a program that involves a global commitment to achieve economic growth, including social and environmental sustainability, 
in all countries. The approved plan has 17 Sustainable Development Goals (SDGs) that aim to promote actions in the coming years in critical areas relevant to society and the environment [1].

To complement the official SDGs, the Sustainable Development Solutions Network (SDSN) and the Bertelsmann Stiftung foundation began to prepare the SDG Index \& Dashboards Report in 2016, which benchmarks the performance of countries regarding SDGs, so that countries can assess their position on compliance with SDGs and set priorities for early action. The overall SDG Index score and goal scores indicate the level of achievement of sustainability.

The 2030 Agenda for Sustainable Development designated 2017 as the International Year of Sustainable Tourism and proposed SDGs. This proposal intended to promote changes in policies, business practices, and consumer behaviors to make tourism more sustainable, thus enabling the achievement of SDGs. This Agenda was an opportunity to create awareness among public and private sectors and society in general about the restrictions in economic growth and the importance of sustainable tourism to economic development, and increase the visibility of sustainable tourism in the business community.

Tourism's ability to promote social sustainability is reflected by the inclusion of tourism in three SDGs: promoting economic growth and employment (Goal 8), sustainable production and consumption (Goal 12), and marine conservation (Goal 14). The cross-cultural nature of tourism and its multiplier effect in many other sectors allows the 17 goals to be attained.

We should ensure that all stakeholders work together, making tourism a catalyst for change, and respect nature, culture, and host communities during travel activities.

Sustainability is increasingly understood as a competitive advantage and a key factor of competitiveness in the tourism industry. Therefore, the analysis of the relationship between these two parameters is crucial.

\section{Literature Review}

Since 2007, the World Economic Forum (WEF) has formulated the Travel and Tourism Competitiveness Index (TTCI), which is published regularly in the Travel and Tourism Competitiveness Report and measures the competitiveness of the main tourist destinations worldwide. The objective of the TTCI is to evaluate factors and policies that make a destination attractive to international tourism. This index is increasingly used by researchers to assess TDC: Kendall and Gursoy [2] examined the relative positioning of eight Mediterranean destinations using a correspondence analysis technique; Gursoy, Baloglu and Chi [3] examined the relative positioning of ten Middle East destinations using a multi-dimensional scaling analysis; Kayar and Kozak [4] compared the competitiveness levels of EU countries with those of Turkey using cluster analysis and multidimensional scaling [4]; and Leung and Baloglu used the same technique in sixteen Asia Pacific destinations [5].

Other researchers developed new tourism competitiveness indexes. For example, Gooroochurn and Sugiyarto [6] used data from the competitiveness monitor scale proposed by the World Travel and Tourism Council, which measures TDC through the development of eight key indicators, using confirmatory factor analysis, in order to calculate an aggregate index; Croes [7] proposed a more accurate TDC index, using the most important factors affecting the competitiveness of island destinations; Croes and Kubickova [8] proposed an alternative TCI, which they apply to the Central American region; some authors used data from the TTCI of the WEF for an global analysis of tourism competitiveness [9-12], while other authors used other information sources pertain to specific destinations [13-15]. In this regard, it is worth mentioning the research works by Mendola and Volo [16] that offered the methodological foundations to build composite indicators in tourism and evaluated a set of currently available composite indicator.

It is also necessary to consider qualitative approaches to measure TDC; some researchers have used data from survey of tourists $[17,18]$ and others researchers have used data from interviews of tourism experts and stakeholders [19-22]. Boroomand, Kazemi and Rankbarian [23] developed a mixed method, a quantitative and qualitative study in order to measure the tourism competitiveness 
of Iran. Others authors have focused their attention on analyzing different approaches in tourism competitiveness [24,25].

Some studies analyzed general factors that affect tourism competitiveness [26-29], while others assessed the effect of specific factors such as the evolution of tourist inflows [30]; globalization [31]; tourism's contribution to economic growth [32]; corruption [33]; air transportation [34]; the competitiveness of international hotel firms [35]; regional systems of innovation [36] or sustainability, which is the focus of our work [37-44].

Goffi, Cucculelli and Masiero [39] tested if sustainability influenced tourism destination competitiveness in developing countries, with the case study Brazil; Pulido-Fernández, Andrades-Caldito and Sánchez-Rivero [41] demonstrated that progress in tourism sustainability does not affect a country's main economic tourism indicator in the short term, and does not constrain profitability and competitiveness; and Pulido-Fernández, Cárdenas-García and Espinosa-Pulido [44] used structural equation models to measure the possible relationships between tourism growth and environmental sustainability, showing that the expansion of tourism translates into an environmental deterioration of the destination and, furthermore, it substantiated that there are specific variables connected to environmental sustainability that contribute to greater tourism growth, so that the relationship between tourism and environmental sustainability is bidirectional.

These studies demonstrated the importance of the relationship between sustainability and TDC and concluded that the former could improve the latter, although the expansion of tourism may contribute to environmental degradation.

Analysing the relationship between TDC and sustainability can help identify the strengths and weaknesses of tourist destinations and highlight the major limitations of competitiveness as well as the pillars and sub-indexes that most contribute to the competitiveness of tourist destinations. Furthermore, this assessment provides policymakers and tourism managers with relevant information that helps them prioritize changes in the tourism industry.

\section{Methods}

The 2017 edition of the Travel and Tourism Competitiveness Report (TTCR) [45] measured different competitiveness indicators in 136 countries using 90 indicators, including political, socioeconomic, structural, environmental, and cultural factors, among others. These indicators were grouped into 14 pillars, and each pillar was classified into four sub-indexes: Enabling Environment, T\&T Policy and Enabling Conditions, Infrastructure, and Natural and Cultural Resources. The sub-indexes were added to develop the TTCI. From a methodological perspective, at each aggregation level, the WEF develops a corresponding composite indicator as an unweighted average of the indicators, pillars or sub-indexes included in the level that immediately preceded it.

Each sub-index was calculated as the unweighted average of the pillars.

$$
\mathrm{SI}_{i}^{(\mathrm{d})}=\frac{\sum_{\mathrm{j}=1}^{\mathrm{m}_{\mathrm{d}}} \mathrm{P}_{\mathrm{ij}}^{(\mathrm{d})}}{\mathrm{m}_{\mathrm{d}}}
$$

where $m_{d}$ is the number of pillars that form each sub-index of tourism competitiveness, and $d$ is the $\mathrm{n}$-th subdomain (for $\mathrm{d}=1$ to 4 ). Therefore, four sub-indexes are obtained.

Furthermore, the overall TTCI for each country is calculated as the unweighted average of the four sub-indexes.

$$
\mathrm{I}_{\mathrm{i}}^{(\mathrm{d})}=\sum_{\mathrm{d}=1}^{\mathrm{n}} \mathrm{SI}_{\mathrm{i}}^{(\mathrm{d})}
$$

$\mathrm{n}$ is the number of sub-indexes that compose the TTCI.

Although pillars are not weighted, they are implicitly weighted because not all sub-indexes have the same number of pillars. The sub-indexes with a smaller number of pillars mean that these 
pillars carry a greater weight in the overall index. Thus, a country with high values in the fourth sub-index (natural and cultural resources), which contains two pillars instead of five as in the case of the first sub-index, would be more positively valued due to this grouping than if the 14 pillars were individually aggregated.

Therefore, it is important to be aware of the implicit weights that are being given and consider whether these are appropriate in accordance to the philosophy of tourism competitiveness.

In this sense we have developed a new synthetic indicator. It is based on a different standardization and aggregation of the pillars $[9,46]$, which enables, on the one hand, further adjustment of the weighting, and on the other hand, evaluation of the state of all other countries in relation to each pillar.

The TDC of a country is determined by multiple criteria. Decision-making methods that simultaneously evaluate different strategies using several criteria constitute multicriteria approaches. The method proposed in this study for calculating the synthetic index uses a goal function proposed by Wierzbicki [47], based on the double reference method. This function normalizes objective functions (pillars) considering two reference levels for each pillar, an aspiration level (desirable value for a certain pillar), and a reservation level (below which the values will not be acceptable) [46].

This type of goal function normalizes all pillars within the range -1 to 2 . The linearity of segments of the goal function allows information that could not be obtained through classical normalization (range between maximum and minimum) to be extracted. Given a country $i$ and a pillar $j, s_{i j}$ equal to -1 indicates that the pillar score for that indicator is the minimum; $\mathrm{s}_{\mathrm{ij}}$ equal to 0 represents the reservation level; $\mathrm{s}_{\mathrm{ij}}$ equal to 1 corresponds to the aspiration level; and $\mathrm{s}_{\mathrm{ij}}$ equal to 2 indicates the maximum score.

With this methodology we obtained different indexes: the weak index $\left(I_{i}^{d}\right)$, strong index $\left(I_{i}^{f}\right)$, and intermediate indexes $\left(I_{i}^{m a}\right)$ were defined for each country:

$$
\begin{gathered}
I_{i}^{d}=\frac{1}{M} \sum_{j=1}^{M} s_{i j} \\
I_{i}^{f}=\min _{j=1, \ldots, M} s_{i j} \\
I_{i}^{m \alpha}=\alpha I_{i}^{d}+(1-\alpha) I_{i}^{f}, 0<\alpha<1
\end{gathered}
$$

The weak index is the arithmetic mean of the scores of the M pillars, the strong index is the minimum pillar score, and the intermediate index is the average between the weak and strong indexes [9]. The weak index measures aggregate competitiveness, allowing substitutability among pillars; the strong index, does not allow substitutability among pillars and therefore measures the state of the pillar with the lowest score; and a series of intermediate indexes composed of the two previous ones, that measure different degrees of tourist competitiveness for different levels of aggregation.

The authors subscribe to the philosophy of 'strong' competitiveness, according to which the weaknesses of certain indicators cannot be offset by the good results obtained in others. In any case, the analysis of all these indices (weak, strong and intermediates) permits a more precise assessment of each country and the study of the factors explaining each situation.

\section{Analysis of Tourism Competitiveness: Contributions of the New Indexes}

Using the above methodology, the tourism competitiveness of 136 countries worldwide was evaluated considering the data published in the 2017 TTCR. The descriptive statistics for the 136 countries are shown in Appendix A: Table A1. The pillars with the strongest correlations were 'human resources and labor market' and 'ICT readiness' and also 'ICT readiness' and 'tourist service infrastructure'. The pillars with the highest scores were 'safety and security' and 'health and hygiene', and 'cultural resources and business travel' and 'air transport infrastructure' were those with the lowest scores. 
According to the WEF methodology, it is equally important to have a high score in any of the pillars with the same implicit weight. However, we can observe that it will be more difficult to obtain high scores for 'cultural resources and business travel' than for 'safety and security' because the average score is lower (Table 1). Our methodology considers this fact; so in this respect, the aspiration values are higher for pillars with higher scores, and countries that does not achieve high scores in these pillars will have a lower overall score.

In fact, if we observe Table 1, we can see that the pillars with higher and lower average values are different if we consider the WEF scores or the normalized scores of our proposed methodology; this is because our methodology uses the aspiration and reservation values in order to normalize. The pillars with the highest and second-highest score was 'safety and security' and 'tourist service infrastructure', respectively, whereas 'cultural resources and business travel' and 'international openness', were the pillars with the lowest and second-lowest score, respectively. This result is relevant because pillars with high and low scores affect tourism competitiveness synthetic index of different countries.

Table 1. Mean values of pillars of the travel and tourism competitiveness index and mean values normalized.

\begin{tabular}{ccc}
\hline Pillars & Mean Values of Pillars WEF [1,7] & $\begin{array}{c}\text { Mean Normalised Values of Pillars } \\
{[-\mathbf{1 , 2}]}\end{array}$ \\
\hline Business environment & 4.529 & 0.491 \\
\hline Safety and security & 5.209 & 0.584 \\
\hline Health and hygiene & 5.125 & 0.533 \\
\hline Human resources and labour market & 4.562 & 0.537 \\
\hline ICT readiness & 4.408 & 0.483 \\
\hline Prioritization of T\&T & 4.487 & 0.529 \\
\hline International Openness & 3.206 & 0.429 \\
\hline Price competitiveness & 4.856 & 0.529 \\
\hline Environmental sustainability & 4.181 & 0.498 \\
\hline Air transport infrastructure & 3.000 & 0.449 \\
\hline Ground and port infrastructure & 3.469 & 0.474 \\
\hline Tourist service infrastructure & 4.059 & 0.554 \\
\hline Natural resources & 3.257 & 0.471 \\
\hline Cultural resources and business travel & 2.323 & 0.414 \\
\hline
\end{tabular}

Another advantage of the aspiration and reserve levels is that their use allows to highlight the differences between the global and regional ranking, what allows us to identified distinctive characteristics among regions. This is because the aspiration and reservation levels may vary globally and regionally since they were obtained from statistical calculations and they depended on the value of the group countries.

Consequently, we calculated the tourism competitiveness synthetic indexes $\left(\mathrm{I}^{\mathrm{d}}, \mathrm{I}^{\mathrm{f}}, \mathrm{I}^{\mathrm{m} 50}, \mathrm{I}^{\mathrm{m} 60}, \mathrm{I}^{\mathrm{m} 70}\right.$, $\mathrm{I}^{\mathrm{m} 80}$ and $\mathrm{I}^{\mathrm{m} 90}$ ) and the TTCI globally and for each of the five regions considered by the UNWTO (the Middle East, Europe, Asia and Pacific, the Americas, and Africa). We compared for each region, the global and regional ranking in each index. While the position of the countries in the WEF rankings did not vary, in ours it did. For illustrative purposes, only the case of the Middle East is show (Table 2). The data concerning the other regions are available upon request.

As we can see in Table 2, the regional and global rankings obtained according TTCI in Middle Eastern countries are the same, while the rankings obtained using weak, intermediate, and strong indexes are different in global and regional rankings. For example, considering the weak index, Oman surpassed Bahrain at the regional level; although both countries improved at this level, but Oman improved more than Bahrain (Appendix B: Table A2). This is primarily due to the 'natural resources' pillar (P13), which is one of the most important pillars. The aspiration and reservation levels of 'natural resources' are lower in the regional than the global level due to the bad situation of the group of countries in this pillar, and Oman managed exceed the aspiration level. 
Table 2. Differences in the ranking of Middle Eastern countries for the different tourism competitiveness indexes based on overall and regional scores.

\begin{tabular}{|c|c|c|c|c|c|}
\hline Economy & TTCI Global & $\begin{array}{c}\text { TTCI } \\
\text { Middle East }\end{array}$ & Economy & $\begin{array}{c}I^{d} \\
\text { Global }\end{array}$ & $I^{d}$ Middle Eas \\
\hline United Arab Emirates & 29 & 1 & United Arab Emirates & 25 & 1 \\
\hline Qatar & 47 & 2 & Qatar & 47 & 2 \\
\hline Bahrain & 60 & 3 & Saudi Arabia & 63 & 3 \\
\hline Saudi Arabia & 63 & 4 & Bahrain & 64 & 5 \\
\hline Oman & 66 & 5 & Oman & 66 & 4 \\
\hline Egypt & 74 & 6 & Egypt & 72 & 6 \\
\hline Jordan & 75 & 7 & Jordan & 79 & 7 \\
\hline Lebanon & 96 & 8 & Lebanon & 96 & 8 \\
\hline Kuwait & 100 & 9 & Kuwait & 106 & 9 \\
\hline Yemen & 136 & 10 & Yemen & 134 & 10 \\
\hline Economy & $\begin{array}{c}I^{f} \\
\text { Global }\end{array}$ & $\begin{array}{c}I^{f} \\
\text { Middle East }\end{array}$ & Economy & $\begin{array}{c}I^{m 50} \\
\text { Global } \\
\end{array}$ & $\begin{array}{c}I^{m 50} \\
\text { Middle East }\end{array}$ \\
\hline United Arab Emirates & 13 & 2 & United Arab Emirates & 19 & 2 \\
\hline Oman & 63 & 1 & Oman & 63 & 1 \\
\hline Egypt & 79 & 6 & Egypt & 74 & 5 \\
\hline Jordan & 96 & 5 & Qatar & 77 & 3 \\
\hline Lebanon & 100 & 3 & Saudi Arabia & 81 & 4 \\
\hline Saudi Arabia & 109 & 7 & Jordan & 86 & 6 \\
\hline Yemen & 119 & 10 & Lebanon & 97 & 8 \\
\hline Qatar & 120 & 4 & Bahrain & 99 & 7 \\
\hline Kuwait & 124 & 9 & Kuwait & 118 & 9 \\
\hline Bahrain & 127 & 8 & Yemen & 132 & 10 \\
\hline
\end{tabular}

In addition, the United Arab Emirates remained in the first position in the four global rankings. However, at the regional level, this country ranked second when we used strong and intermediate indexes and it was surpassed by Oman. This result is due to the 'price competitiveness' pillar (P8). Aspiration and reservation levels were higher due to the good level of this region in this pillar. The score for the United Arab Emirates was 5.023, which was higher than the global reservation level (4.394). Nonetheless, the reservation level in the Middle East was 5.197 because the score of all countries for this pillar was high so that the score of the United Arab Emirates became bad compared to the rest. Therefore, the score for the United Arab Emirates was below the reservation value, whereas the score for Oman was above the aspiration level. Moreover, the score for the 'environmental sustainability' (P9) was higher for Oman because the score for the Middle Eastern region was lower for this pillar.

The proposed methodology allows differences between regions to be assessed. The analyzed regions had different characteristics, which could lead to different weights, as performed by WEF using the Global Competitiveness Index (GCI), which distributed weights according to the stage of development of each country based on the gross domestic product (GDP) per capita. These weights were justified because, although all the pillars are critical for the economies of these countries, some pillars are more relevant than others, depending on the level of development of each country. For this reason, higher weights can be attributed to pillars that are more relevant to an economy given its particular level of development [48].

Similarly, the pillars of tourism competitiveness affect countries in different ways according to their stage of development. For this reason, the strategy adopted to improve the tourism competitiveness of a developed country is different from that used for a developing country.

It should be noted that the GCI weights assigned by the WEF to the countries that were in the transition stages changed gradually as these countries developed. This approach ensures that higher weights are attributed to regions with higher potential for competitiveness and penalizes countries with less economic development [49].

This methodology was applied until 2017. The GCI assigns the same weight to the 12 pillars considering the complexity of prioritizing policies in the current context. This methodology is 
significantly different from a previous methodology, which assigned greater weight to the enabling conditions in low-income countries and a higher weight to innovation and sophistication in developed countries to indicate that the competitiveness strategies adopted by each country should vary according to the level of development. Under this premise, the WEF seeks to provide the same starting conditions and encourage the comprehensive development of all countries [50].

The reasoning is that, as the Fourth Industrial Revolution progresses, all competitiveness factors will have a similar impact on the competitiveness of countries, regardless of their income levels. Automation will likely reduce the possibility of development in countries that depend on low labor costs in manufacturing. In this respect, Rodrik [51] found that economic growth in many developing countries was determined by services, whereas recently industrialized countries began to deindustrialize much earlier than Western countries. At the same time, information and communication technologies are reducing information barriers and allowing the rapid transfer of concepts, technologies, and products worldwide, opening new opportunities for developing economies. Based on these data, the current GCI is less prescriptive about the path to prosperity, rewarding countries that advance and penalizing those that neglect any aspect of competitiveness, regardless of their stage of development.

We followed the same strategy and used similar weights for countries at different stages of development. We are also in line with the idea of penalizing countries that neglect aspects of tourism competitiveness. In this respect, the strong index penalizes countries that do not achieve reservation values in important pillars, so countries with low scores in essential pillars, which required the most urgent solutions, can be identified. The proposed methodology exposes the countries that offset low scores with high scores on other pillars.

\section{Relationship between Tourism Competitiveness and Other Tourism Indicators}

We analyze the relationship between tourism competitiveness and other tourism indicators to assess possible relationships between the most competitive and the most attractive countries for tourism. We performed a ranking analysis based on different variables, including 'international tourist arrivals', 'international tourism receipts' and 'average spending per international tourist', provided by UNWTO; and 'T\&T industry GDP', 'T\&T industry Employment', 'T\&T industry Share of GDP', and 'T\&T industry Share of Employment' provided by the World Travel \& Tourism Council, Tourism Satellite Account Research. Tourism competitiveness tended to improve as the 'T\&T industry GDP' or 'the international tourist arrivals' increased (Appendix C: Figures A1 and A2).

The TTCI was analyzed in greater detail using the tourism GDP of the evaluated countries, which were classified into four categories:

- Low income: $<2000$ US $\$$ million (60 countries)

- Medium-low income: between 2000 and 10,000 US\$ million (36 countries)

- Medium-high income: between 10,000 and 20,000 US\$ million (17 countries)

- High income: more than 20,000 US\$ million (20 countries)

To determine significant differences, the TTCI scores and pillars of competitiveness for each of these groups of countries were analyzed (Appendix C: Figures A3 and A4). The pillar scores increased as the tourism revenues of the countries increased. This trend was more pronounced for 'natural and cultural resources' and less pronounced for 'T\&T policy and conditions'. The 'enabling environment' pillar had the highest average scores for all levels and similar scores among all countries; however, the scores of this pillar were slightly higher in medium-high-income countries than in high-income countries.

The pillars with the highest variability at all levels were 'air transport infrastructure' (P10) and 'cultural resources and business travel' (P14), whereas those with the lowest variability at all levels were 'business environment' (P1), 'safety and security' (P2), 'price competitiveness' (P8), and 'environmental sustainability' (P9). The scores of most pillars increased as tourism revenues increased, except for the pillars considered more homogeneous and 'human resources and labor market' (P4). 
The pillars with the lowest scores were 'international openness' (P7) (at all levels), 'air transport infrastructure', (P10) 'ground and port infrastructure', (P11) and 'natural resources' (P13) for low and medium-low-income countries and 'cultural resources and business travel' (P14) for all countries except for high-income countries.

However, according to the results and the strategy followed by the WEF, we do not consider it appropriate to allocate weights based on the characteristics of the tourist magnitudes of the countries.

\section{Analysis of Sustainability: Relevance to Tourism Competitiveness}

The SDG Index measures the sustainability of different countries, its global score indicates the level of achievement of sustainability. The countries with the lowest and highest scores in SDG Index 2017 (Appendix D: Tables A3 and A4) were located in Africa and Europe, respectively. Therefore, sustainability was analyzed by region to assess possible patterns (Appendix D: Figure A5).

The analysis of SDGs indicated that the scores for Europe were usually higher than those of other regions in the SDG index and in almost all the SDGs, except for SDG12 (scores were lowest), SDG13 (scores were lower than in the Americas), SDG16 (scores were similar to those of Middle Eastern countries), and SDG17 (scores were slightly higher than in Asia-Pacific countries). Africa had the lowest overall score and the lowest score for most SDGs, except for SDG5 and SDG11 (higher than in Middle Eastern countries), SDG10 and SDG16 (scores were higher than in the Americas), SDG13 (score was higher than in Asian and Middle Eastern countries), SDG12 (score was higher than in all other regions), and SDG15 and SDG17.

The SDGs with the highest scores were SDG1, SDG3, SDG4, and SDG6, and those with the lowest scores were SDG9 and SDG14. The SDGs with the highest inter-region variability were SDG1, SDG3, SDG5, SDG6, and SDG9, and those with the lowest variability were SDG2 and SDG14.

Several studies found a strong relationship between sustainability and tourism competitiveness. Therefore, this relationship was analyzed in the present paper using the obtained tourism competitiveness indexes $\left(\mathrm{I}^{\mathrm{d}}, \mathrm{I}^{\mathrm{f}}, \mathrm{I}^{\mathrm{m} 50}, \mathrm{I}^{\mathrm{m} 60}, \mathrm{I}^{\mathrm{m} 70}, \mathrm{I}^{\mathrm{m} 80}, \mathrm{I}^{\mathrm{m} 90}\right.$ and TTCI) and the SDG index, for both global and regional. First of all we carry out the global analysis.

First, we assessed the relationship between the SDGs and the tourism competitiveness indexes and found that the correlation between these indexes and SDGs was significant, except for SDG15 and SDG17.

The relationship between the SDG index and the tourism competitiveness indexes showed a stronger correlation of TTCI and the weak index with SDG Index than between the strong index and SDG Index (Figure 1). However, an independent analysis by region and global rankings yielded different results (Figures 2-6).

Middle Eastern countries were at the bottom of the sustainability ranking and had intermediate tourism competitiveness values although, as the substitutability among pillars was reduced (by approaching the strong index), countries lost their position in tourism competitiveness (from quadrant 2 to quadrant 3), whereas the sustainability ranking remained constant because we did not apply our methodology (Figure 2). Sustainability increased as tourism competitiveness increased.

All European countries, except for Bosnia and Herzegovina, had a high sustainability ranking. With respect to tourism competitiveness, countries had scores above and below the average, and lost competitiveness as the substitutability among pillars was reduced. There was a growing trend between these two variables.

In American countries, there was a growing trend between tourism competitiveness and sustainability (Figure 4). Most countries were located between quadrant 1 (high ranking) and quadrant 3 (low ranking).

Most African countries presented a low ranking for sustainability and competitiveness, and sustainability tended to increase as tourism competitiveness increased. It is worth noting that, by applying the strong index instead of the TTCI, African countries increased their ranking because the 
former penalized countries that achieved high TTCI values by offsetting among pillars with high and low scores.

In Asia-Pacific countries, sustainability tended to increase as tourism competitiveness increased. Most countries as in Americas, were located between quadrants 1 and 3. It should be emphasized that countries with a low overall sustainability ranking had higher tourism competitiveness when we applied the strong index, whereas countries with a high overall ranking had lower tourism competitiveness.

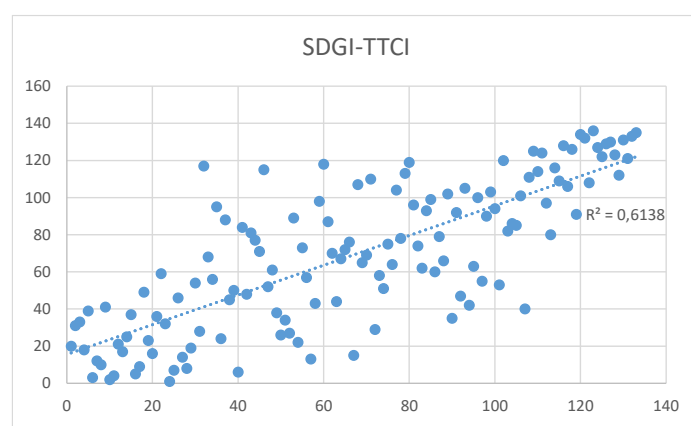

(a)

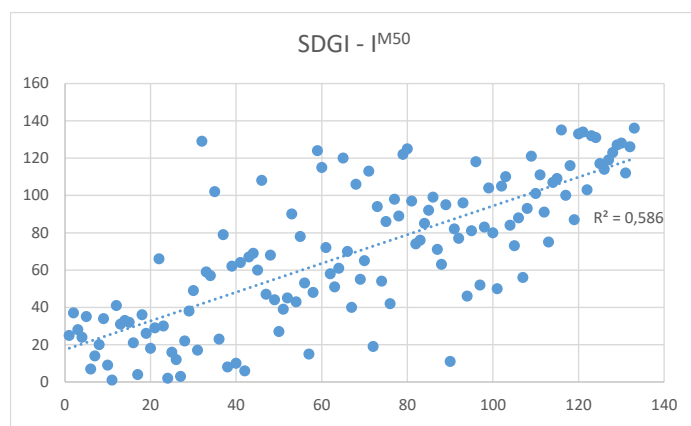

(c)

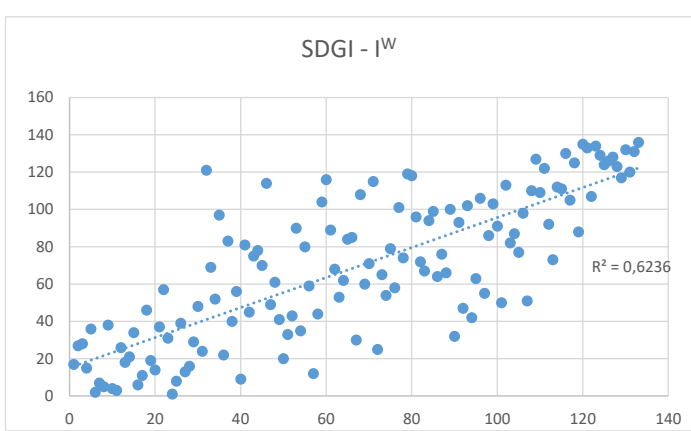

(b)

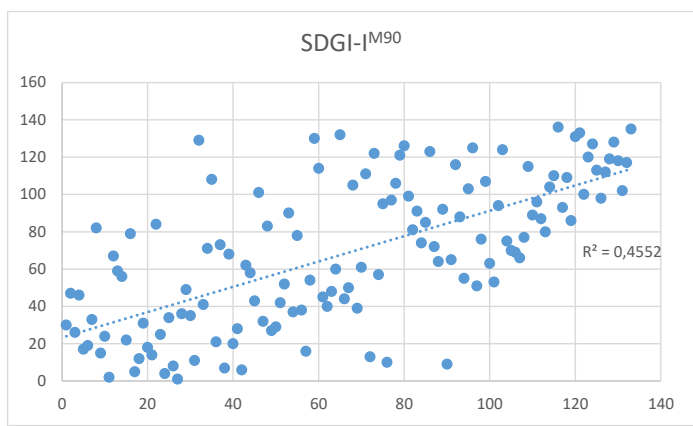

(d)

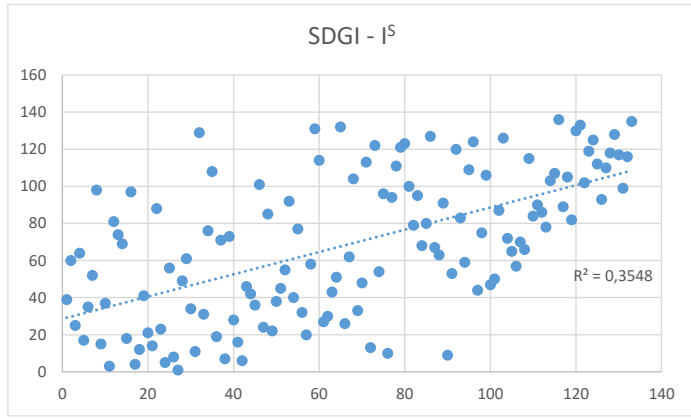

(e)

Figure 1. (a) Relationship between sustainability and tourism competitiveness (TTCI). (b) Relationship between sustainability and tourism competitiveness $\left(\mathrm{I}^{\mathrm{W}}\right)$. (c) Relationship between sustainability and tourism competitiveness $\left(\mathrm{I}^{\mathrm{M} 50}\right)$. (d) Relationship between sustainability and tourism competitiveness $\left(\mathrm{I}^{\mathrm{M} 90}\right)$. (e) Relationship between sustainability and tourism competitiveness $\left(\mathrm{I}^{\mathrm{S}}\right)$. 


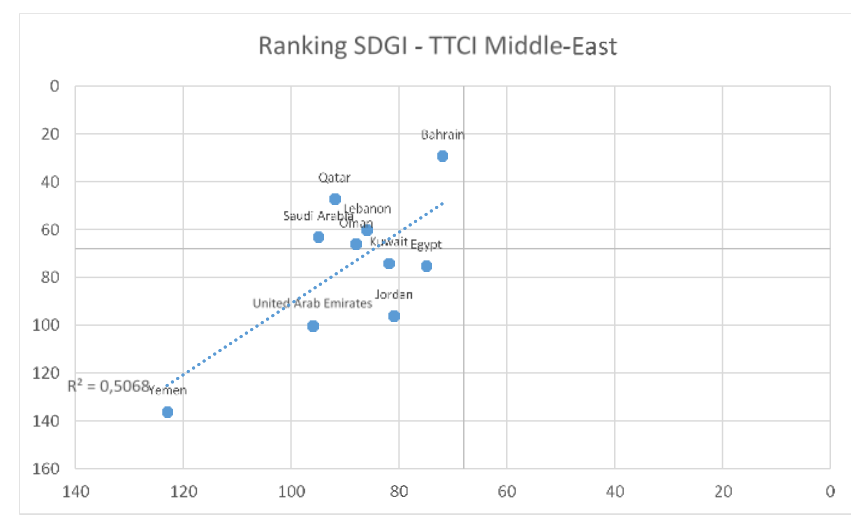

(a)

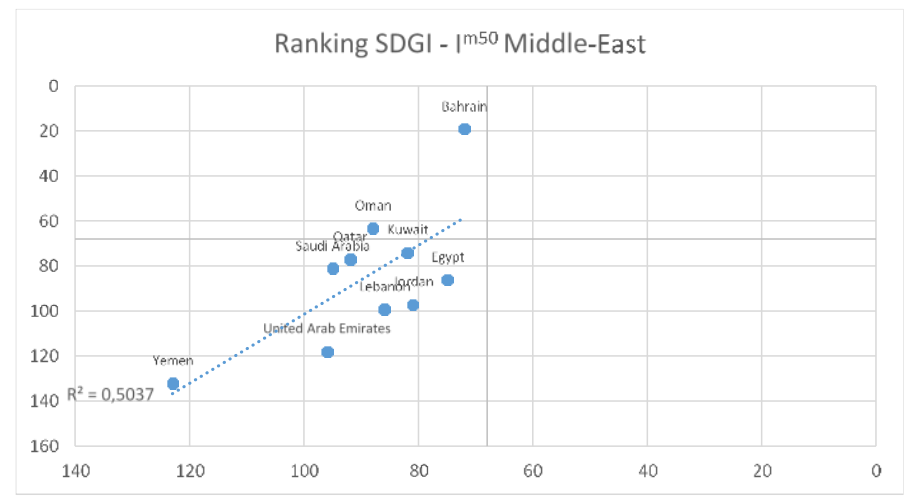

(b)

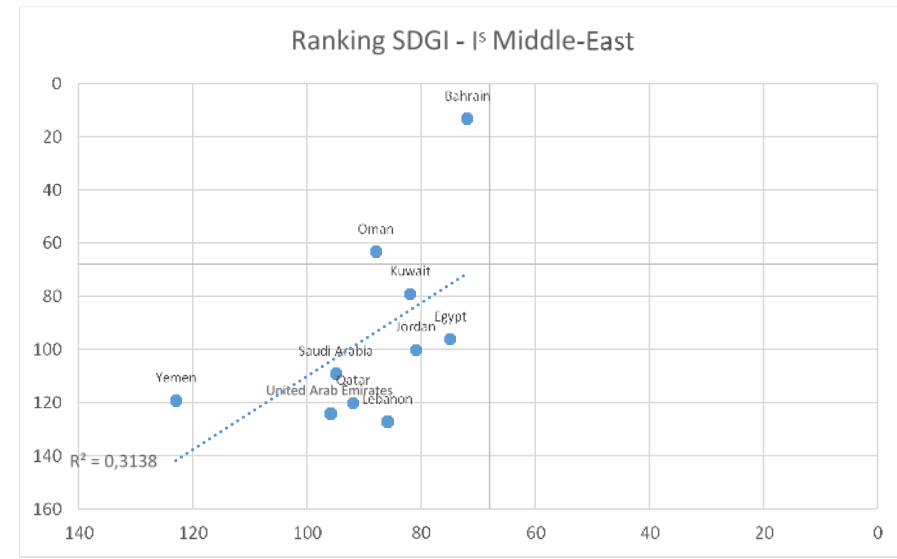

(c)

Figure 2. (a) Relationship between sustainability and tourism competitiveness (TTCI) in the Middle-East. (b) Relationship between sustainability and tourism competitiveness $\left(\mathrm{I}^{\mathrm{m} 50}\right)$ in the Middle-East. (c) Relationship between sustainability and tourism competitiveness $\left(\mathrm{I}^{\mathrm{s}}\right)$ in the Middle-East. 


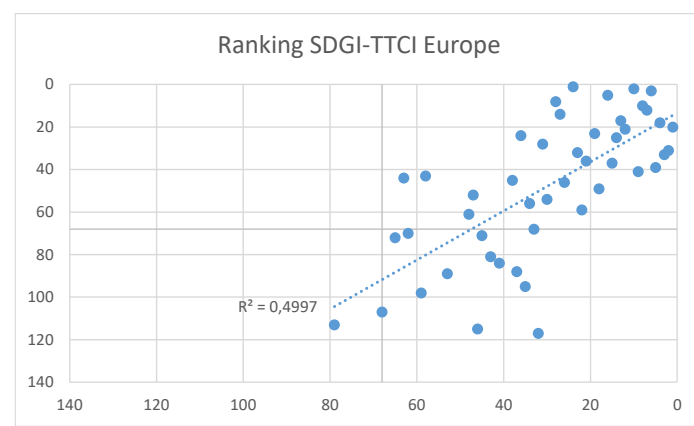

(a)

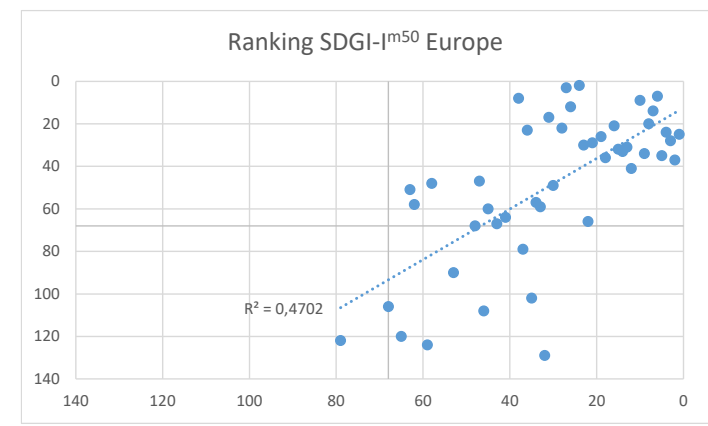

(b)

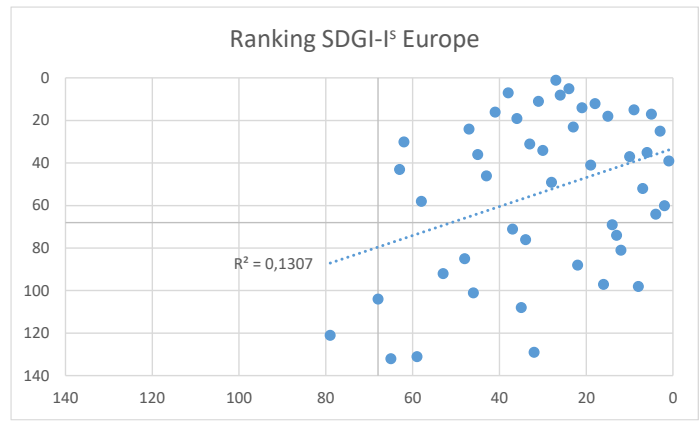

(c)

Figure 3. (a) Relationship between sustainability and tourism competitiveness (TTCI) in Europe. (b) Relationship between sustainability and tourism competitiveness $\left(\mathrm{I}^{\mathrm{M} 50}\right)$ in Europe. (c) Relationship between sustainability and tourism competitiveness $\left(\mathrm{I}^{\mathrm{S}}\right)$ in Europe.

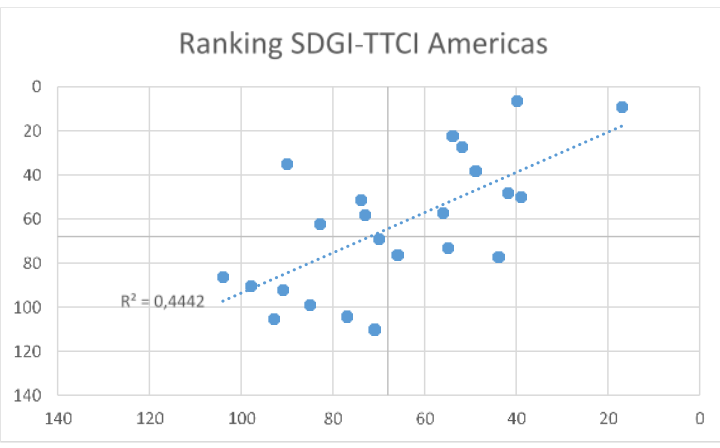

(a)

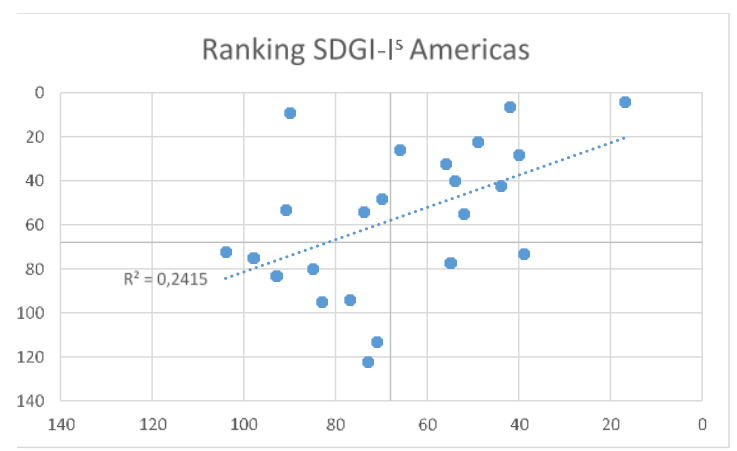

(b)

Figure 4. (a) Relationship between sustainability and tourism competitiveness (TTCI) in America. (b) Relationship between sustainability and tourism competitiveness $\left(\mathrm{I}^{\mathrm{S}}\right)$ in America.

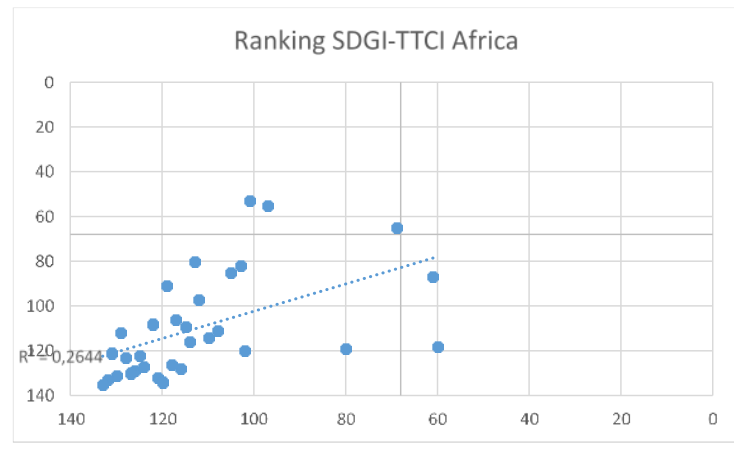

(a)

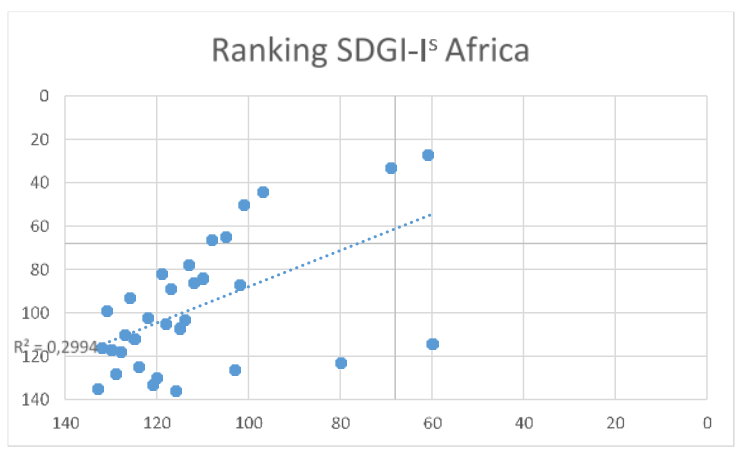

(b)

Figure 5. (a) Relationship between sustainability and tourism competitiveness (TTCI) in Africa. (b) Relationship between sustainability and tourism competitiveness $\left(\mathrm{I}^{\mathrm{S}}\right)$ in Africa. 


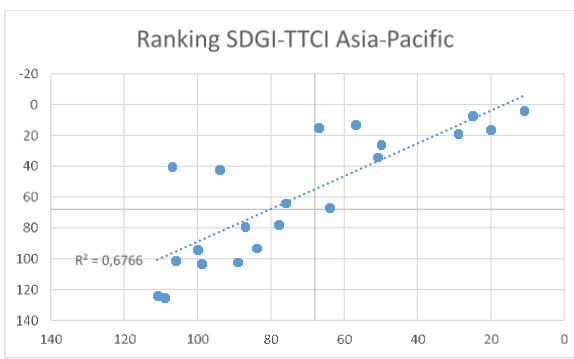

(a)

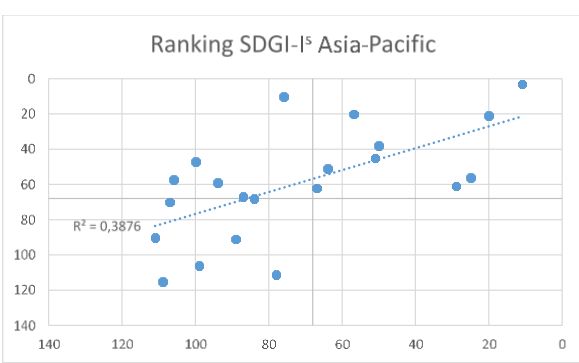

(b)

Figure 6. (a) Relationship between sustainability and tourism competitiveness (TTCI) in Asia-Pacific. (b) Relationship between sustainability and tourism competitiveness $\left(\mathrm{I}^{\mathrm{S}}\right)$ in Asia-Pacific.

A different behaviour has been observed in each region, which can be collected in a more complete way with the tourist competitiveness synthetic indexes $\left(\mathrm{I}^{\mathrm{d}}, \mathrm{I}^{\mathrm{f}}, \mathrm{I}^{\mathrm{m} 50}, \mathrm{I}^{\mathrm{m} 60}, \mathrm{I}^{\mathrm{m} 70}, \mathrm{I}^{\mathrm{m} 80}\right.$ and $\left.\mathrm{I}^{\mathrm{m} 90}\right)$, as we already demonstrated in Section 4, Table 2; these differences were due to reservation and aspiration levels. Therefore, we have performed a regional analysis with the regional rankings. As in Section 4, in order not to saturate the reader, we show by way of example the case of the Middle East (Figure 7). Data may be required for the other regions.

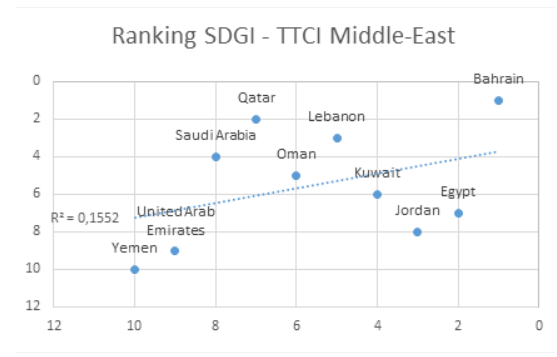

(a)

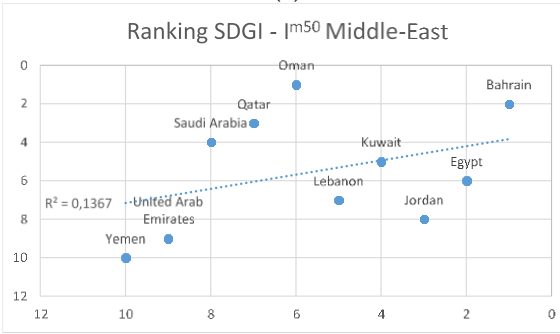

(c)

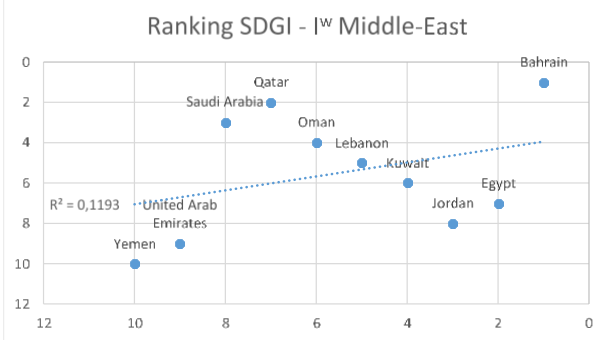

(b)

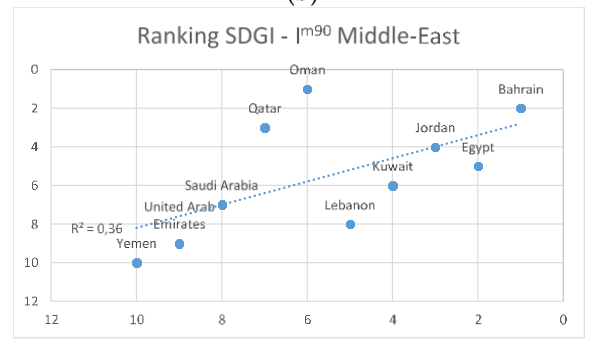

(d)

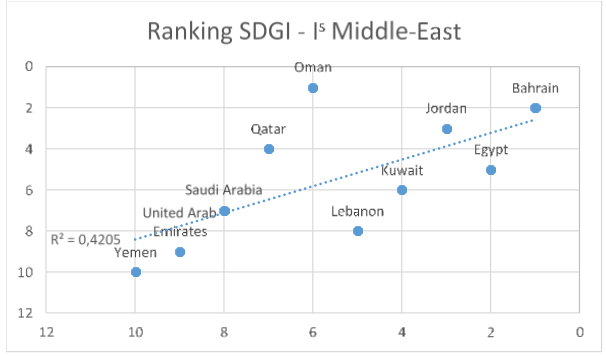

(e)

Figure 7. (a) Relationship between sustainability and tourism competitiveness (TTCI) in Middle Eastern countries. (b) Relationship between sustainability and tourism competitiveness (TTCI) in Middle Eastern countries. (c) Relationship between sustainability and tourism competitiveness (TTCI) in Middle Eastern countries. (d) Relationship between sustainability and tourism competitiveness (TTCI) in Middle Eastern countries. (e) Relationship between sustainability and tourism competitiveness (TTCI) in Middle Eastern countries. 
Figure 7 shows that at the regional level there was a stronger relationship between sustainability and tourism competitiveness when we used the strong index, that is, as pillar substitutability is restricted there is a greater correlation between these magnitudes. This fact happens because the countries that improve positions using a strong index have a more homogeneous tourist competitiveness and that benefits sustainability to a greater extent. Having only one pillar with a very good level and the rest of the pillars with a very poor score, implies negative consequences for sustainability because the pillars that have a bad score can be harmful to sustainability.

\section{Conclusions}

This study has analyzed the relationship between tourism competitiveness worldwide and sustainability. Different synthetic indexes of tourism competitiveness were developed based on the data published in the TTCR for 2017 using a multicriteria double reference point method; these indexes improve some TTCI deficiencies. With the current WEF methodology, the results of the TTCI may lead to misleading conclusions, because there may be countries which obtain excellent results due only to certain pillars offsetting for the bad results in other pillars. Which can also have negative effects on sustainability. The application of the proposed methodology in this study avoids this problem, since a country will remain in the last positions of the ranking as long as the poor results of its indicators do not improve. Sustainability was evaluated using the Sustainable Development Index (SDG Index) developed by the SDSN and the Bertelsmann Stiftung Foundation. Moreover, a joint analysis of these two magnitudes was conducted at the global and regional levels. The proposed method allowed differences between geographical regions to be estimated and to elaborate different regional rankings.

The analysis of the tourism competitiveness for each of the five regions considered by UNWTO (the Middle East, Europe, Asia and Pacific, the Americas, and Africa) indicated that the position occupied by each country at the regional level was different from the overall ranking within a specific region. This finding is because the reservation and aspiration values varied as they were obtained from statistical calculations based on the scores of countries, indicating differences between regions and the need to perform evaluations by region.

To determine aspiration and reservation levels in a statistical way (according to the country values) offers us a relative ranking; if reference levels are determined by a panel of experts, we would not only get a ranking of countries, but it would also be possible to identify which countries are competitive and which are not. It lets us measure competitiveness not in relative terms, but in relation to the reservation value. This is a great challenge, since countries have very different characteristics and these levels should have agreement among experts since governments seek to improve their positions in the ranking and use these data to generate national policies.

In addition, the analysis of sustainability revealed that African countries occupied the lowest rankings, whereas European countries had the highest rankings. Therefore, sustainability was also analyzed by region to assess possible patterns. The assessment of SDGs indicated that European countries usually presented the highest overall scores and the highest scores for most SDGs, except for SDG12 (ensure sustainable consumption and production patterns), which was lower than in all other regions. In contrast, African countries presented the lowest overall score and the lowest score for most SDGs, except for SDG 12, which was higher than in all other regions. This shows that the more developed countries should pay more attention to improve this SDG.

The relationship between sustainability and tourism competitiveness was analyzed. There was a positive and significant correlation between all tourism competitiveness indexes and SDG Index and most of SDGs. Globally there was a higher correlation of the TTCI and the weak index $\left(\mathrm{I}^{\mathrm{d}}\right)$ with the SDG Index than between the strong index and the SDG Index. However, an independent analysis by region and global rankings yielded different results. In some regions, the countries lost tourism competitiveness as the substitutability among pillars was reduced (by approaching the strong index) (Europe and Middle East) while Africa gained tourism competitiveness, it is due to the strong index that penalized the countries that achieved high tourism competitiveness scores by establishing offsets 
between pillars with high and low scores. It is worth highlighting that Asia-Pacific countries with a low overall sustainability gained tourism competitiveness when the strong index was applied, whereas countries with a high overall ranking lost tourism competitiveness.

Furthermore, regarding the relationship with sustainability, at a regional level as pillar substitutability is restricted there was a greater correlation between sustainability and tourism competitiveness. This fact happens because countries that improve their ranking position when we use strong index, have a more homogeneous tourist competitiveness and that benefits sustainability to a greater extent.

These analysis allowing managers and politicians to design specific strategies to improve areas that need attention. In this sense, the strong index can be considered a complementary index that avoids substitutability among pillars with high and low scores. So consequently this index identifies countries with low rankings in critical pillars, which require the most urgent solutions; allowing all stakeholders to work jointly to improve the competitiveness of the tourism industry in their national economies, thereby contributing to national growth and prosperity. Having only one pillar with a very good level and the rest of the pillars with a very poor score, implies negative consequences for sustainability too because the pillars with a bad score will be harmful to sustainability.

Author Contributions: Conceptualization, B.R.-D. and J.I.P.-F.; methodology, B.R.-D.; writing, B.R.-D.; data curation, B.R.-D.; formal analysis, B.R.-D. and J.I.P.-F.; and writing-review, J.I.P.-F. All authors have read and agreed to the published version of the manuscript.

Funding: This research received no external funding.

Conflicts of Interest: The authors declare no conflict of interest.

\section{Appendix A}

Table A1. Descriptive statistics of the pillars of the Travel and Tourism Competitiveness Index.

\begin{tabular}{lcll}
\hline & Pillars & Mean & Standard Deviation \\
\hline $\mathbf{1}$ & Business environment & 4.529 & 0.678 \\
\hline 3 & Safety and security & 5.209 & 0.937 \\
\hline 4 & Health and hygiene & 5.125 & 1.228 \\
\hline 5 & Human resources and labour market & 4.562 & 0.626 \\
\hline 6 & ICT readiness & 4.408 & 1.220 \\
\hline 7 & Prioritization of T\&T & 4.487 & 0.829 \\
\hline 8 & International Openness & 3.206 & 0.916 \\
\hline 9 & Price competitiveness & 4.856 & 0.693 \\
\hline 10 & Environmental sustainability & 4.181 & 0.563 \\
\hline 11 & Air transport infrastructure & 3.000 & 1.193 \\
\hline 12 & Ground and port infrastructure & 3.469 & 1.125 \\
\hline 13 & Tourist service infrastructure & 4.059 & 1.281 \\
\hline 14 & Natural resources & 3.257 & 0.997 \\
\hline
\end{tabular}




\section{Appendix B}

Table A2. Comparison between Oman and Bahrain, normalized values global and regional.

\begin{tabular}{cccccccccccccccc}
\hline Global & $\mathbf{1}$ & $\mathbf{2}$ & $\mathbf{3}$ & $\mathbf{4}$ & $\mathbf{5}$ & $\mathbf{6}$ & $\mathbf{7}$ & $\mathbf{8}$ & $\mathbf{9}$ & $\mathbf{1 0}$ & $\mathbf{1 1}$ & $\mathbf{1 2}$ & $\mathbf{1 3}$ & $\mathbf{1 4}$ & $\mathbf{I}^{\mathbf{d}}$ \\
\hline Reservation & 4.12 & 4.64 & 4.44 & 4.15 & 3.59 & 3.97 & 2.48 & 4.39 & 3.76 & 2.05 & 2.55 & 2.87 & 2.43 & 1.36 & \\
\hline Aspiration & 4.95 & 5.86 & 6.12 & 4.94 & 5.45 & 5.04 & 4.09 & 5.35 & 4.57 & 3.84 & 4.33 & 5.01 & 4.01 & 2.88 \\
\hline Values & & & & & & & & & & & & & & \\
\hline Bahrain & 5.50 & 5.70 & 5.17 & 4.66 & 6.01 & 4.32 & 2.87 & 5.53 & 3.83 & 3.46 & 5.21 & 4.93 & 1.67 & 1.32 \\
\hline Oman & 5.11 & 6.49 & 5.43 & 4.15 & 5.05 & 4.43 & 2.18 & 5.48 & 3.71 & 2.99 & 3.88 & 4.10 & 2.62 & 1.94 \\
\hline Normalized Values & & & & & & & & & & & & & & & \\
\hline Bahrain & 1.269 & 0.870 & 0.436 & 0.647 & 1.360 & 0.323 & 0.246 & 1.111 & 0.074 & 0.786 & 1.328 & 0.961 & $-0.529-0.1130 .515$ \\
\hline Oman & 1.079 & 1.555 & 0.590 & -0.000 & 0.788 & 0.433 & -0.200 & 1.080 & -0.021 & 0.523 & 0.746 & 0.577 & 0.123 & 0.382 & 0.499 \\
\hline Regional & $\mathbf{1}$ & $\mathbf{2}$ & $\mathbf{3}$ & $\mathbf{4}$ & $\mathbf{5}$ & $\mathbf{6}$ & $\mathbf{7}$ & $\mathbf{8}$ & $\mathbf{9}$ & $\mathbf{1 0}$ & $\mathbf{1 1}$ & $\mathbf{1 2}$ & $\mathbf{1 3}$ & $\mathbf{1 4}$ & $\mathbf{I}^{\mathbf{d}}$ \\
\hline Reservation & 4.31 & 3.50 & 5.34 & 4.06 & 4.18 & 4.06 & 1.83 & 5.20 & 3.37 & 2.47 & 2.96 & 3.69 & 1.85 & 1.31 & \\
\hline Aspiration & 5.59 & 6.37 & 5.67 & 4.79 & 5.87 & 5.05 & 2.90 & 5.79 & 4.13 & 3.87 & 4.71 & 4.96 & 2.51 & 2.19 \\
\hline Values & & & & & & & & & & & & & & \\
\hline Bahrain & 5.50 & 5.70 & 5.17 & 4.66 & 6.01 & 4.32 & 2.87 & 5.53 & 3.83 & 3.46 & 5.21 & 4.93 & 1.67 & 1.32 & \\
\hline Oman & 5.11 & 6.49 & 5.43 & 4.15 & 5.05 & 4.43 & 2.18 & 5.48 & 3.71 & 2.99 & 3.88 & 4.10 & 2.62 & 1.94 & \\
\hline Normalized Values & & & & & & & & & & & & & & \\
\hline Bahrain & 0.934 & 0.766 & -0.039 & 0.819 & 1.123 & 0.256 & 0.979 & 0.567 & 0.596 & 0.706 & 1.215 & 0.977 & -0.208 & 0.012 & 0.547 \\
\hline Oman & 0.631 & 1.194 & 0.281 & 0.117 & 0.517 & 0.375 & 0.331 & 0.480 & 0.439 & 0.371 & 0.525 & 0.328 & 1.025 & 0.721 & 0.559 \\
\hline & & & & & & & & & & & &
\end{tabular}

\section{Appendix C}

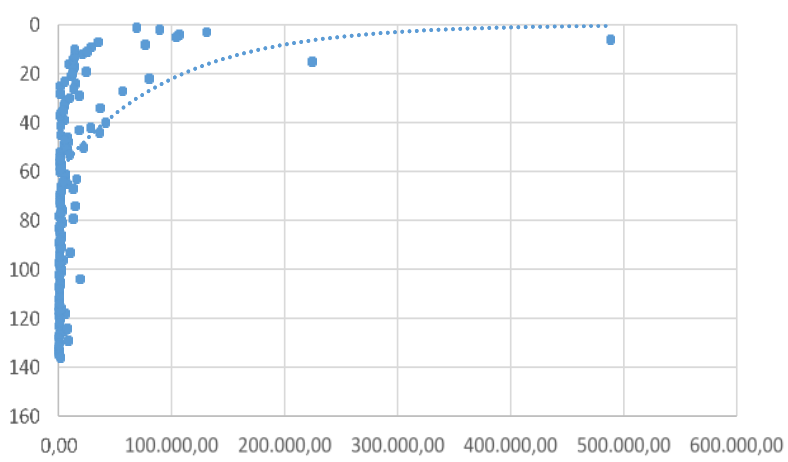

Figure A1. Ranking TTCI-GDP T\&T industry.

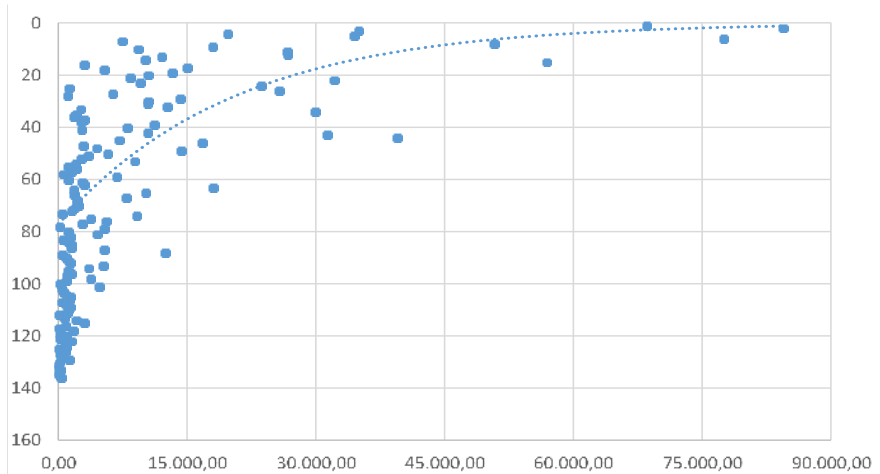

Figure A2. Ranking TTCI-International tourist arrivals (thousands). 


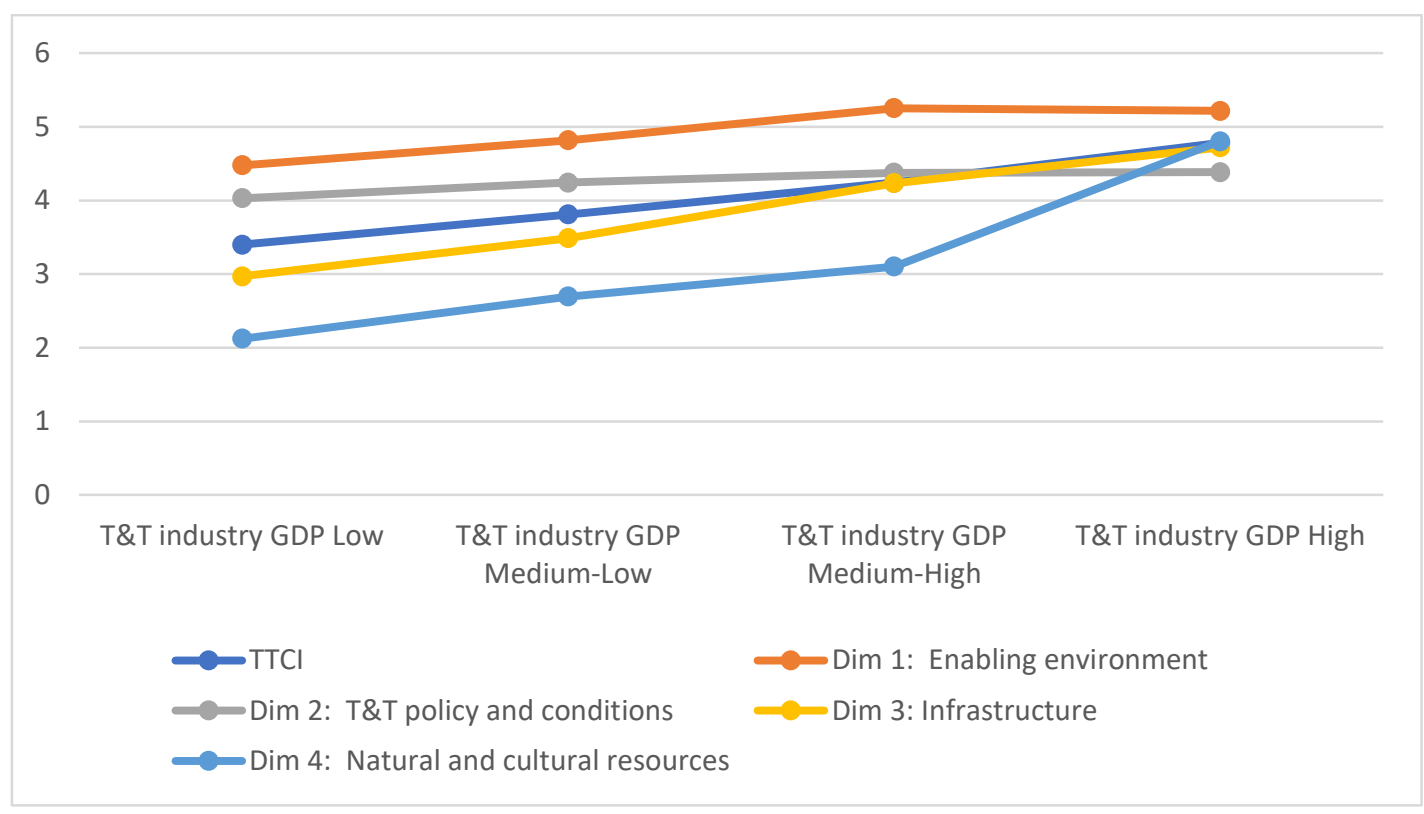

Figure A3. TTCI values and pillars according to tourism GDP levels.

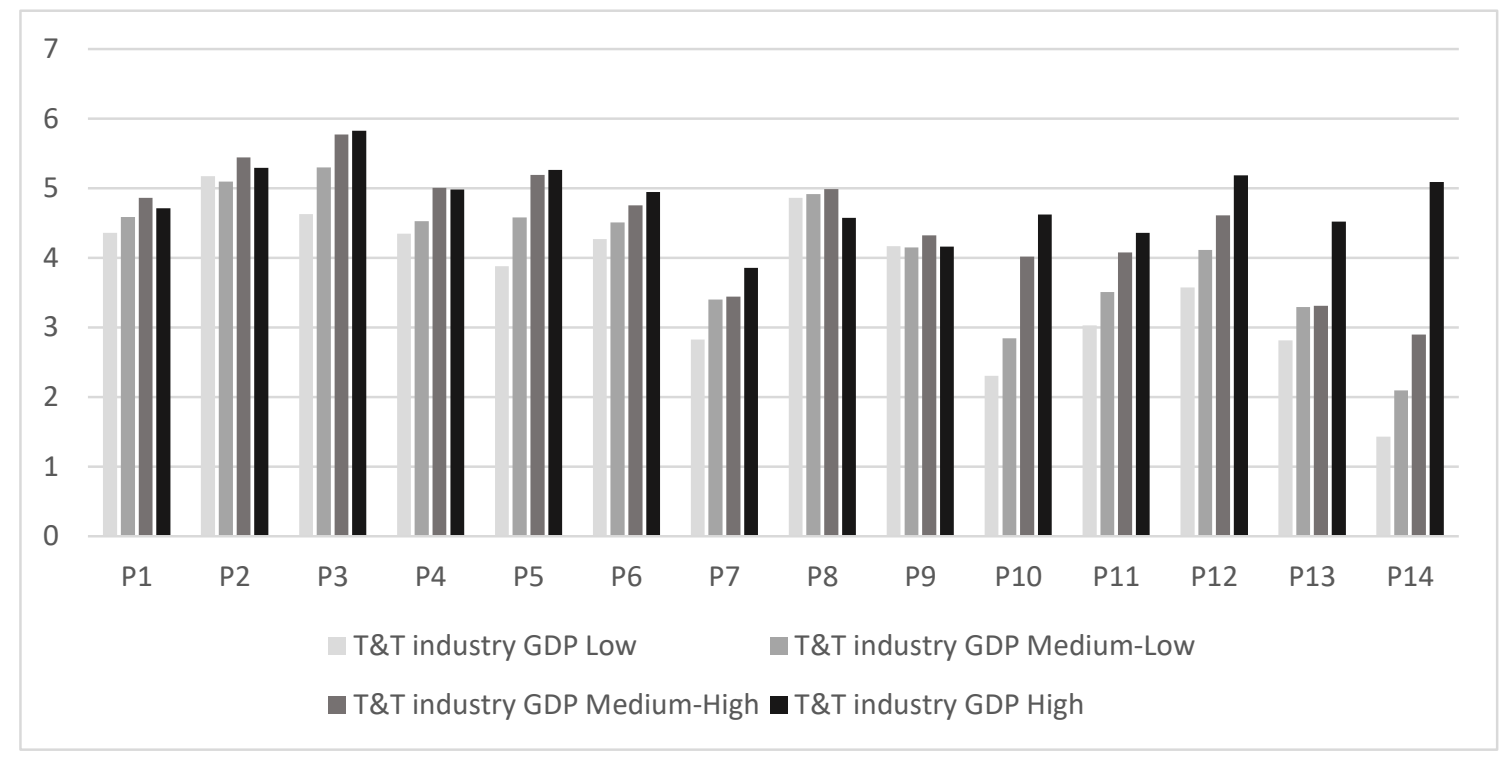

Figure A4. Pillars of competitiveness according to tourism GDP levels.

\section{Appendix D}

Table A3. Lowest values of the Sustainability Development Index.

\begin{tabular}{cccccc}
\hline Economy & GDP T\&T Industry & Region & Income_Group GDP & SDG Index Score (0-100) & Ranking SDGI \\
\hline Chad & Low income & Africa & Low income & 41.5 & 133 \\
\hline Congo, Democratic Rep. & Low income & Africa & Low income & 42.7 & 132 \\
\hline Madagascar & Low income & Africa & Low income & 43.5 & 47.1 \\
\hline Sierra Leone & Low income & Africa & Low income & 47.8 & 131 \\
\hline Gambia, The & Low income & Africa & Low income & 48.0 & 129 \\
\hline Malawi & Low income & Africa & Low income & 48.5 & 128 \\
\hline Mali & Low income & Africa & Low income & 48.6 & 127 \\
\hline Nigeria & Medium-low income & Africa & Low income & 49.2 & 126 \\
\hline Mozambique & Low income & Africa & Low income & 49.5 & 125 \\
\hline Benin & Low income & Africa & Low income & & 124 \\
\hline
\end{tabular}


Table A4. Highest values for the Sustainability Development Index.

\begin{tabular}{cclccc}
\hline Economy & GDP T\&T Industry & Region & Income_Group GDP & SDG Index Score (0-100) & Ranking SDG \\
\hline France & High income & Europe & High income & 80.3 & 10 \\
\hline Slovenia & Low income & Europe & High income & 80.5 & 9 \\
\hline Switzerland & Medium-high income & Europe & High income & 81.2 & 81.4 \\
\hline Austria & High income & Europe & High income & 81.7 & 6 \\
\hline Germany & High income & Europe & High income & 81.9 & 5 \\
\hline Czech Republic & Medium-low income & Europe & High income & 83.9 & 4 \\
\hline Norway & Medium-high income & Europe & High income & 84.0 & 3 \\
\hline Finland & Medium-low income & Europe & High income & 84.2 & 2 \\
\hline Denmark & Medium-low income & Europe & High income & 85.6 &
\end{tabular}

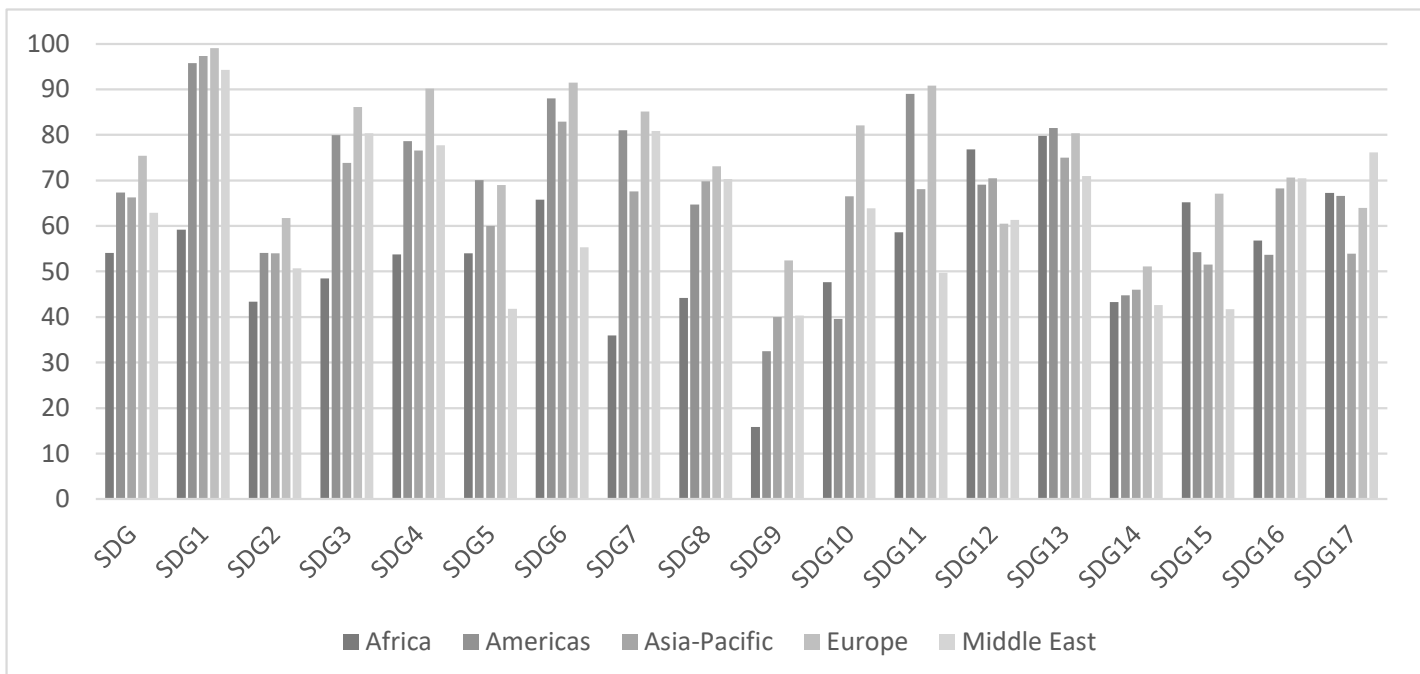

Figure A5. Sustainability Development Goal scores by geographical region.

\section{References}

1. United Nations. The Sustainable Development Goals Report 2019; United Nations: New York, NY, USA, 2019.

2. Kendall, K.W.; Gursoy, D. A managerial approach to positioning and branding: Eponymous or efficient. Tour. Anal. 2007, 12, 473-483. [CrossRef]

3. Gursoy, D.; Baloglu, S.; Chi, C.G. Destination competitiveness of Middle Eastern countries: An examination of relative positioning. Anatolia 2009, 20, 151-163. [CrossRef]

4. Kayar, C.H.; Kozak, N. Measuring destination competitiveness: An application of the travel and tourism competitiveness index (2007). J. Hosp. Mark. Manag. 2010, 19, 203-216. [CrossRef]

5. Leung, X.Y.; Baloglu, S. Tourism competitiveness of Asia Pacific destinations. Tour. Anal. 2013, 18, 371-384. [CrossRef]

6. Gooroochurn, N.; Sugiyarto, G. Competitiveness indicators in the travel and tourism industry. Tour. Econ. 2005, 11, 25-43. [CrossRef]

7. Croes, R. Measuring and explaining competitiveness in the context of small island destinations. J. Travel Res. 2011, 50, 431-442. [CrossRef]

8. Croes, R.; Kubickova, M. From potential to ability to compete: Towards a performance-based tourism competitiveness index. J. Destin. Mark. Manag. 2013, 2, 146-154. [CrossRef]

9. Pulido-Fernández, J.I.; Rodríguez-Díaz, B. Reinterpreting the World Economic Forum's global tourism competitiveness index. Tour. Manag. Perspect. 2016, 20, 131-140. [CrossRef]

10. Martín, J.C.; Mendoza, C.; Román, C. A DEA travel-tourism competitiveness index. Soc. Indic. Res. 2017, 130, 937-957. [CrossRef]

11. Gómez-Vega, M.; Picazo-Tadeo, A.J. Ranking world tourist destinations with a composite indicator of competitiveness: To weigh or not to weigh? Tour. Manag. 2019, 72, 281-291. [CrossRef] 
12. Nazmfar, H.; Eshghei, A.; Alavi, S.; Pourmoradian, S. Analysis of travel and tourism competitiveness index in middle-east countries. Asia Pac. J. Tour. Res. 2019, 24, 501-513. [CrossRef]

13. Zhang, H.; Gu, C.L.; Gu, L.W.; Zhang, Y. The evaluation of tourism destination competitiveness by TOPSIS \& information entropy-A case in the Yangtze River Delta of China. Tour. Manag. 2011, 32, 443-451.

14. Lopes, A.P.F.; Muñoz, M.M.; Alarcón-Urbistondo, P. Regional tourism competitiveness using the PROMETHEE approach. Ann. Tour. Res. 2018, 73, 1-13. [CrossRef]

15. Gu, T.; Ren, P.; Jin, M.; Wang, H. Tourism destination competitiveness evaluation in Sichuan province using TOPSIS model based on information entropy weights. Discret. Contin. Dyn. Syst. Ser. S 2019, 12. [CrossRef]

16. Mendola, D.; Volo, S. Building composite indicators in tourism studies: Measurements and applications in tourism destination competitiveness. Tour. Manag. 2017, 59, 541-553. [CrossRef]

17. Bahar, O.; Kozak, M. Advancing destination competitiveness research: Comparison between tourists and service providers. J. Travel Tour. Mark. 2007, 22, 61-71. [CrossRef]

18. Cracolici, M.F.; Nijkamp, P. The attractiveness and competitiveness of tourist destinations: A study of Southern Italian regions. Tour. Manag. 2009, 30, 336-344. [CrossRef]

19. Chens, C.Y.; Sok, P.; Sok, K. Evaluating the competitiveness of the tourism industry in Cambodia: Self-assessment from professionals. Asia Pac. J. Tour. Res. 2008, 13, 41-66. [CrossRef]

20. Bornhorst, T.; Ritchie, J.B.; Sheehan, L. Determinants of tourism success for DMOs \& destinations: An empirical examination of stakeholders' perspectives. Tour. Manag. 2010, 31, 572-589.

21. Liu, X. A study on the Competitiveness of Urban Tourism Destinations Taking Loudi City in Hunan Providence for Example. Inf. Technol. J. 2013, 12, 2905-2912.

22. Andrades, L.; Dimanche, F. Destination competitiveness in Russia: Tourism professionals' skills and competences. Int. J. Contemp. Hosp. Manag. 2019, 31, 910-930. [CrossRef]

23. Boroomand, B.; Kazemi, A.; Rankbarian, B. Designing a Model for Competitiveness Measurement of Selected Tourism Destinations of Iran (The Model and Rankings). J. Qual. Assur. Hosp. Tour. 2019, 20, 491-506. [CrossRef]

24. Dwyer, L.; Cvelbar, L.K.; Mihalič, T.; Koman, M. Integrated Destination Competitiveness Model: Testing Its Validity and Data Accessibility. Tour. Anal. 2014, 19, 1-17. [CrossRef]

25. Sainaghi, R.; Phillips, P.; Zavarrone, E. Performance measurement in tourism firms: A content analytical meta-approach. Tour. Manag. 2017, 59, 36-56. [CrossRef]

26. Reisinger, Y.; Michael, N.; Hayes, J.P. Destination competitiveness from a tourist perspective: A case of the United Arab Emirates. Int. J. Tour. Res. 2019, 21, 259-279. [CrossRef]

27. Kozegar, L.; Hesam, M.; Kazemi, M. An analysis of influential factors on tourism destinations competitiveness. J. Environ. Manag. Tour. 2017, 8, 393-406.

28. Montero-Muradas, I.; Oreja-Rodríguez, J.R. Factores competitivos determinantes del liderazgo turístico de España en 2015. Cuad. Tur. 2017, 465-488. [CrossRef]

29. Michael, N.; Reisinger, Y.; Hayes, J.P. The UAE's tourism competitiveness: A business perspective. Tour. Manag. Perspect. 2019, 30, 53-64. [CrossRef]

30. De la Peña, M.; Núñez-Serrano, J.A.; Turrión, J.; Velázquez, F.J. A New Tool for the Analysis of the International Competitiveness of Tourist Destinations Based on Performance. J. Travel Res. 2019, 58, 207-223. [CrossRef]

31. Ivanov, S.; Webster, C. Globalisation as a driver of destination competitiveness. Ann. Tour. Res. 2013, 43, 624-650. [CrossRef]

32. Webster, C.; Ivanov, S. Transforming competitiveness into economic benefits: Does tourism stimulate economic growth in more competitive destinations? Tour. Manag. 2014, 40, 137-140. [CrossRef]

33. Das, J.; Dirienzo, C. Tourism competitiveness and corruption: A cross-country analysis. Tour. Econ. 2010, 16, 477-492. [CrossRef]

34. Khan, S.A.R.; Qianli, D.; SongBo, W.; Zaman, K.; Zhang, Y. Travel and tourism competitiveness index: The impact of air transportation, railways transportation, travel and transport services on international inbound and outbound tourism. J. Air Transp. Manag. 2017, 58, 125-134. [CrossRef]

35. Mendieta-Peñalver, L.F.; Perles-Ribes, J.F.; Ramón-Rodríguez, A.B.; Such-Devesa, M.J. Is hotel efficiency necessary for tourism destination competitiveness? An integrated approach. Tour. Econ. 2018, 24, 3-26. [CrossRef]

36. Romão, J.; Nijkamp, P. Impacts of innovation, productivity and specialization on tourism competitiveness-a spatial econometric analysis on European regions. Curr. Issues Tour. 2019, 22, 1150-1169. [CrossRef] 
37. Cucculelli, M.; Goffi, G. Does sustainability enhance tourism destination competitiveness? Evidence from Italian Destinations of Excellence. J. Clean. Prod. 2016, 111, 370-382. [CrossRef]

38. Dias, J.G. Environmental sustainability measurement in the Travel \& Tourism Competitiveness Index: An empirical analysis of its reliability. Ecol. Indic. 2017, 73, 589-596.

39. Goffi, G.; Cucculelli, M.; Masiero, L. Fostering tourism destination competitiveness in developing countries: The role of sustainability. J. Clean. Prod. 2019, 209, 101-115. [CrossRef]

40. Berinde, S.R.; Corpadean, A.G. Assessing the Sustanainable Room for Growth for a Particular Romanian Tourism Area of Business: The Case of Accommodation Businesses. Sustainability 2019, 11, 243. [CrossRef]

41. Pulido-Fernández, J.I.; Andrades-Caldito, L.; Sánchez-Rivero, M. Is sustainable tourism an obstacle to the economic performance of the tourism industry? Evidence from an international empirical study. J. Sustain. Tour. 2015, 23, 47-64. [CrossRef]

42. Rodríguez, M.; Espino, T.F. Determining the Sustainability Factors and Performance of a Tourism Destination from the Stakeholders' Perspective. Sustainability 2016, 8, 951. [CrossRef]

43. Iraldo, F.; Testa, F.; Lanzini, P.; Battaflia, M. Greening competitiveness for hotels and restaurants. J. Small Bus. Enterp. Dev. 2017, 24, 607-628. [CrossRef]

44. Pulido-Fernández, J.I.; Cárdenas-García, P.J.; Espinosa-Pulido, J.A. Does environmental sustainability contribute to Tourism growth? An analysis at the country level. J. Clean. Prod. 2019, 213, 309-319. [CrossRef]

45. World Economic Forum. The Travel Tourism Competitiveness Report 2017; WEF: Geneva, Switzerland, 2017.

46. Luque, M.; Miettinen, K.; Eskelinen, P.; Ruiz, F. Incorporating Preference Information in Interactive Reference Point Methods for Multiobjective Optimization. Omega Int. J. Manag. Sci. 2009, 37, 450-462. [CrossRef]

47. Wierzbicki, A.P.; Makowski, M.; Wessels, J. (Eds.) Model-Based Decision Support Methodology with Environmental Applications; Kluwer Academic Publishers: Dordrecht, The Netherlands, 2000.

48. World Economic Forum. The Global Competitiveness Report 2014-2015; WEF: Cologny, Switzerland, 2014.

49. Chacón, F. Indicadores Internacionales de Desarrollo: Seguimiento e Interpretación Para Costa Rica; Universidad de Costa Rica; Observatorio del Desarrollo Índice de Competitividad Global: San José, CA, USA, 2015.

50. World Economic Forum. The Global Competitiveness Report 2018-2019; WEF: Cologny, Switzerland, 2018.

51. Rodrik, D. Premature Deindustrialization; Working Paper 20935, NBER Working Paper Series; NBER: Cambridge, MA, USA, 2015. 